\title{
Palestinian State Maps and Imperial Technologies of Staying Put
}

\author{
Jess Bier
}

To some, maps are an ultimate expression of modernity. A map combines text, images, data, and analytical relationships. Maps are intended to serve as models of a material world that is said to be "out there," a world that, it is assumed, can be known by observation and geometric abstraction (Dodge, Kitchin, and Perkins 2009, 2011; Crampton 2010; Pickles 1995). Cartography also illustrates the links between modernity and colonialism. Cartographic practices are often geared toward obtaining control over people and land by producing knowledge about them. Maps have a long association with conquest. They are made not just of the world as it is believed to be but of a world that the mapmakers, and their patrons, might bring into being (Cosgrove 2008; Winichakul 1994; Wood 2010). Historically, large swaths of territory might be mapped in anticipation of an invasion that was yet to come. Maps also were used to commensurate different parts of an empire by depicting them with standardized systems of colors and symbols. Egypt, India, and the United Kingdom might be combined into one atlas, as if they were trophies to be admired. In this way, maps made possible both the imagination and the administration of empire. As Matthew $\mathrm{H}$. Edney (1997: 2) has said of British colonial India: "The empire exists because it can be mapped; the meaning of empire is inscribed into each map."

However, maps are never as seamless or eternal as they are intended to be. Borders shift. Markets fail. Soldiers defect. Swaths of land sink into the sea. To draw a border is to demarcate a self and an other, to create negative space and therefore invite resistance, and to inspire competing maps. To follow the process of making maps, then, is to begin to delineate how efforts to deliberate, rationalize, and ana-

My thanks go to the editors, the anonymous reviewers, Miriyam Aouragh, Sally Wyatt, Bas van Heur, Willem Schinkel, and my colleagues. I am also grateful to Jayne, my parents, Ben, Ethan, Rachel, and our extended family for their ongoing support. 
lyze might be their own undoing. Similarly, although scientific knowledge has pretentions to universality (Haraway 1988; Rose 1997), a concerted engagement with practices of observation shows that empirical knowledge is infused with social and material landscapes. The spaces where observations take place fundamentally shape the observer, the act of seeing, and what is observed.

This article outlines one set of empirical practices to demonstrate how colonial landscapes shape the production of digital knowledge. This shaping is not due to any fault of the cartographers, who employ current methods in professional cartography in innovative and rigorous ways. Instead, it is emblematic of digital practices more broadly. For despite broad rhetoric about their emancipatory potential, digital and social media are by no means exempt from systemic power and injustice, including racism and orientalism (Aouragh 2015a, 2015b; Aouragh and Chakravartty 2016). To understand why requires delving into the technical details of cartography, to pinpoint how empirical practices are embedded within landscapes of power. This study of cartography therefore places geographical literature in critical cartography in dialogue with science and technology studies (STS) research on technological and scientific practices. ${ }^{1}$ In so doing, it complements and extends both the important literature on the rhetoric and aesthetics of maps and work on the politics of maps in state building, including urban and environmental planning. ${ }^{2}$

In the process, I travel through the practices that inform one particularly courageous map, or, more specifically, one set of map data: the 2008 files supplied by the Palestinian Authority (PA) Ministry of Planning to an international openaccess cartographic database. These data are representative of those used in a broad swath of the maps made by the PA and related nongovernmental organization (NGO) cartographers as they seek to establish a distinctly Palestinian form of empirical knowledge in the West Bank. To analyze the data, I draw out and specify one aspect of the Palestinian political practice of sumud (steadfastness), which I call stasis, or "the ability to remain in place." I do so to draw a contrast with a commonly held view of maps — namely, that they are objective representations that are separate from people and land. Instead, my analysis shows that the

1. For critical cartography, see Crampton 2010; Crampton and Krygier 2006; Kwan 2002; Pavlovskaya 2002; and St. Martin and Wing 2007. For STS research on technological and scientific practices, see Bijker 1995; Bijker, Hughes, and Pinch 2012; Latour 1993; Latour and Woolgar 1986; MacKenzie 2006; and Wyatt 2003.

2. On the rhetoric and aesthetics of maps, see Abourahme and Ribeiro 2010; Cosgrove 2008; Leuenberger and Schnell 2010; and Wallach 2011. On the politics of maps, see, e.g., Leuenberger 2012; Leuenberger and El-Atrash 2014; and Yiftachel 2009. 
landscapes of the Israeli occupation come to integrally shape what can be known about the occupation itself.

Although it is common to speak of using international science and technology to "solve" conflict and injustice, such efforts are fully enmeshed in the contexts of violence in which they operate. The study of stasis enables an understanding of the role of geographic context in shaping science and technology, and it is thus central to understandings of modern knowledge far beyond the West Bank and Gaza Strip and far beyond cartography. It is particularly relevant in the broader context of the enforced mobilities that are an integral part of global capitalism and in the ongoing relationships between media, knowledge, and empire (Aouragh and Chakravartty 2016). By seeing the act of "staying put" as the goal of a relational process of interacting with the landscape, rather than an obvious fact, it is possible to outline specific ways that imperial forms of control continue to limit alternative knowledges and more imaginative maps.

In the face of immense political and social pressure, Palestinian cartographers are doing some of the most theoretically innovative and interesting contemporary work in data visualization. In the process, they draw on a variety of influences in digital geographic information science (GIS) cartography, as well as a series of projects in the late 1990s, during which cartographers in the West Bank helped to develop a Palestinian national mapping program, building data infrastructure in the service of nationalist ideals (Tesli 2008). Yet rather than making use of data produced in the everyday administration of an established nation, Palestinian cartographers, precisely through their maps, have sought to bring into being a legal, internationally recognized state of Palestine. These efforts have been subject to enduring challenges due to the intervention of international groups in a process that dates back centuries, most recently through twentieth-century British imperialism and the ongoing Israeli occupation.

In what follows, I analyze three core features of one set of PA map data (fig. 1) the borders, roads, and urban areas - to outline the implications of stasis for empirical knowledge practices writ large. Drawing upon six months of fieldwork in PA and NGO cartographic offices in the West Bank, I introduce the material effects of boundary making through an exploration of the mapping of the boundary of the West Bank immediately after the colonial British Mandate period (1920-48). I next turn to roads, to demonstrate how British colonial maps have affected the geographic scales used in PA maps during the period from the founding of the PA to the end of the second intifada Palestinian uprising (1994-2005). Then I turn to the negative, or background, space, which is often depicted as featureless or blank, to investigate the influence of the Israeli occupation on Palestin- 
ian maps in recent years (2005-present). Thus this article deals with the relations among three stages of mapmaking: British imperialism, the rise of GIS, and the contemporary period, when GIS maps have become a core tool for daily governance. Each period also corresponds to an early stage of map production or, better yet, to a step in the process of establishing the digital infrastructure that makes it possible to produce maps at all. The procedure begins with the drawing of the boundaries that are intrinsic to sovereignty, one condition of possibility for much professional cartography. It then addresses the gathering of historical maps and data that are necessary to begin making a single map. These steps are followed by efforts to conduct fieldwork with Global Positioning System (GPS) devices to update the data on the ground.

\section{On Steadfastness and Staying Put}

Analyzing such practices through the lens of stasis, this article draws on, but also departs from, the rich history of sumud. Lori Allen (2008: 456) refers to sumud as a "nationalistically inflected form of stoicism," and it is central to antioccupation struggles. For example, to further sumud, one might work to highlight the social and cultural contributions of Palestinians in the face of ongoing and violent efforts to remove them or work to develop infrastructure and institutions that support group identity and survival in the landscape (Van Teeffelen and Giacaman 2008). Conceptions of sumud have broadened greatly since the term's initial inception at the 1978 Arab League summit, and they currently inspire a host of practices that seek to sustain a Palestinian presence in the Occupied Territories and beyond.

Sumud is central to understanding contemporary cartographic efforts in the West Bank, but it is also broadly theoretically relevant for anyone concerned with the spatial turn in social theory. It is particularly relevant to questions of how modernity and modern knowledge are embedded in capitalist and colonial landscapes across space and time. To that end, the study of stasis, as one key aspect of sumud, is particularly salient to contemporary critical and social theory. The term stasis can carry negative connotations of stagnation or being stuck. However, it also brings with it a positive sense that deserves greater attention in critical studies of development and resistance than it has received to date: namely, that of generative stability achieved in relation to ongoing change. In this reclaimed form, stasis refers to struggles to establish and maintain a presence within a geographical landscape, as well as the work of maintaining the landscape itself. Its use can thereby incorporate research on the production of landscape and geographic scale 
(Smith 1992), including the scale of the nation (Balibar 1990). In addition, it draws further critical focus toward the numerous efforts to control populations by maintaining a separation between landscapes and the people who inhabit them (see, e.g., Mitchell 2002). ${ }^{3}$ The study of stasis therefore addresses and provides greater nuance in analyzing the practices that speak to one major concern of postcolonial theory: the role that knowledge plays in maintaining imperial control.

The study of stasis also complements critiques of professional cartography, which is arguably far better suited to mapping static political territories than to mapping mobile populations (Crampton 2001, 2010; Crampton and Krygier 2006). As such, this article contributes to analyses of knowledge making in the everyday, notably including Allen's (2013) analysis of the role of evidence in the work of human rights organizations and Linda Quiquivix's (2013) work on cartographic practices of "figuring it out" (see also Quiquivix 2014). In addition, it draws on mobility studies literature, including work on immobilities and Internet spaces (Cresswell 1999, 2011; Söderström et al. 2013), as well as the complex interactions between off-line and online mobility, including the ways that mobilities can produce particular places in specific ways (Aouragh 2011a, 2011b; Harker 2009; Tawil-Souri and Aouragh 2014).

However, stasis is not simply equivalent to either stillness or immobility, and the positive or negative implications of stasis must themselves become the objects of study, since the relationships between stasis and mobility might vary widely across space and time. For although discussions of Palestinian mobility tend to focus on local or regional movement (see, e.g., B'Tselem 2004), stasis is of equal concern. In addition, the mobility and stasis of PA cartographers and institutions must be viewed in light of multiple geographic scales, including the international scale. Indeed, PA internationalism is evident in the generally high international mobilities of Palestinian elites. Many of those I worked with had studied for advanced degrees abroad, including, for example, in Canada, the Netherlands, Russia, and the United States, to name only a small sample. However, the process of travel was often fraught with uncertainties. On a regional level, the Israeli military routinely sets up checkpoints to control both entrances to the West Bank and routes within it. Short trips can stretch to hours, and Palestinians are frequently detained indefinitely and without charge (Amnesty International 2003; B'Tselem 2004; UNOCHA-OPT 2009, 2012). Such uncertainty not only restricts

3. My focus on stasis is certainly not meant as a corrective for sumud. Indeed, it is intended precisely to minimize any potential infringement upon sumud's ongoing history in Palestinian movements. I use stasis precisely to avoid claiming ownership over sumud, while also drawing out its spatial and geographical aspects. 
their mobility, but it also poses a challenge to efforts to produce stasis and stability. Internationally, in addition to the discrimination commonly found at checkpoints and airports, there is an ongoing prohibition against Palestinians operating their own planes without Israeli approval (which is rarely forthcoming) (PLO and State of Israel 1995). Furthermore, the ability to travel is not always a privilege, since many Palestinians must go abroad to find work or visit family members who themselves cannot enter the Occupied Territories. So extensive international mobility can be a symptom of, rather than a remedy to, challenges to Palestinian stasis within the West Bank (Aouragh 2011a; 2011b: 41-42).

The textured relationships between mobility and stasis can also be seen in the shifting locations of cartographic organizations. PA offices are currently headquartered primarily in Ramallah, in a move that is symbolic of the broader effort to force Palestinians out of Jerusalem. Over the past decade, a variety of factors have combined to push Palestinian organizations ever further from Jerusalem. Several of the NGOs I worked with were originally located there, but Jerusalem increasingly has been closed to Palestinians from the West Bank, and many cartographic NGOs moved east into the outskirts of the city so that all of their employees could continue their work. Once construction on the Israeli Separation Wall began, with the aim of separating the majority of the West Bank from Israel, the NGOs moved again, from the immediate vicinity of the wall toward prominent West Bank cities like Ramallah and Bethlehem.

Regimes of mobility and stasis are thus complexly linked, particularly in relation to changes in institutional infrastructure that are made possible in part through maps. An analysis of Palestinian cartography therefore demonstrates the importance of better understanding the production of these shifting landscapes. And production is central, for, like maps, landscapes must be made. Movement is often depicted as occurring "on top of" landscapes that are depicted as a simple blank background. However, PA cartographers don't simply travel through preexisting territories. The spaces they move through are changed by, and also change, their movements. That is why the appearance of staying put, or remaining in place, requires ongoing work in dynamic fields that are at once both social and material (Mitchell 2002). Allen (2008: 456) makes this clear when she notes that, in "conditions where the routine and assumptions of daily life are physically disrupted ... everyday life in Palestine - in its everydayness - is itself partly the result of concerted, collective production." 4 This insight is especially relevant to

4. For a more extensive exploration of stasis, see Bier 2017, which also draws on this article. 
the production of the geographic landscapes that are so fundamental to the occupation's disruptions, landscapes that are themselves foundational to an occupation that is often depicted as a struggle over land.

\section{Toeing the Border Line: The Occupied West Bank Boundary}

It is precisely the ongoing work of production, however, that becomes hidden in many objects of knowledge making. As with graphs, tables, and lists, one characteristic of empirical maps is that they tend to obscure their lineage. To begin to recover the labor and institutions that help constitute these seemingly innocuous documents and visualizations, I now turn to an analysis of the map in figure 1. Figure 1 is a screenshot of a map of the West Bank as it appears in a common GIS program. ${ }^{5}$ Data layers such as roads, districts, and built-up (urban) areas are visualized. The roads appear as thick black lines, district boundaries as thin gray lines, and built-up areas as darkly shaded regions around major cities (see also fig. 5). In the program, the design of the map is somewhat flexible, and it can be changed by the user. However, the data also have intrinsic empirical properties, like shape and direction, built into them. So, for example, if one clicks on a border line, the program can display the geographic coordinates of that point. In addition, the program can be used to perform analyses, like determining the length of the border line or the size of the area that it encircles.

The data for this map come from the PA Ministry of Planning. They were provided in a standardized format, for international use, to the International Steering Committee for

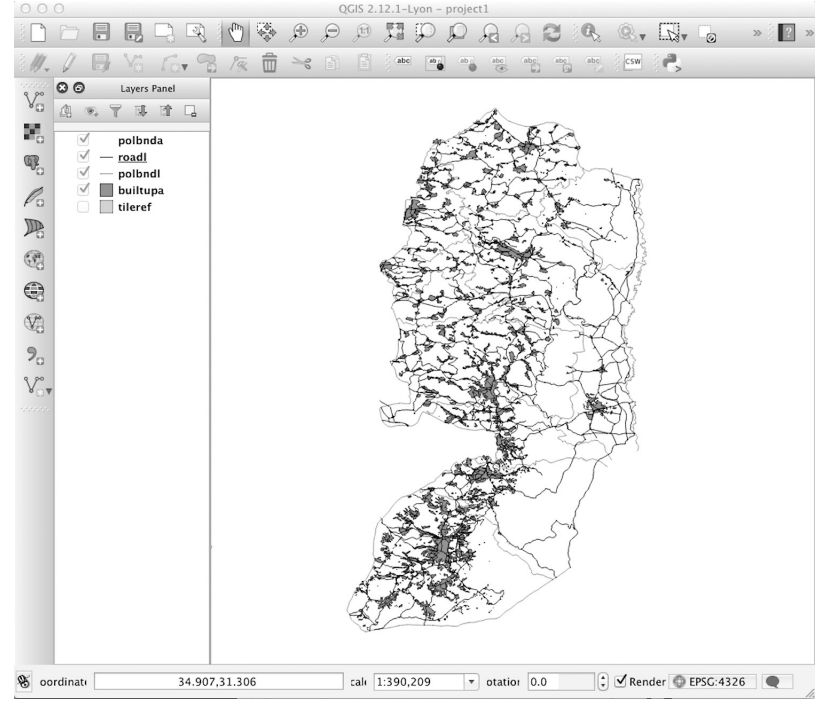

Figure 1 A screenshot of a GIS map of Palestinian Authority data from 2008, depicting major roads and urban areas in the West Bank and Gaza. For a more detailed view, see figure 5. Map by the author. Data appear courtesy of Global Map of Palestine @ ISCGM / Palestinian National Authority, Ministry of Planning, Geographic Center and Technical Support, www.mopad.pna.ps/en/ (accessed March 2, 2016).

Global Mapping (ISCGM), which has ties to the United Nations. In quality and execution, the data thus are commensurable with the data sets provided by 167

5. The figure is shown in QGIS, an open-source GIS program. It exhibits similar features overall to ArcGIS, the licensed program that is favored by many government agencies, but whose costs are prohibitive for individual users. 
other countries. Yet their standardized form hides the ways that the unique context and practices of the West Bank can shape the data. That is to suggest not that the Palestinian data are somehow less rigorous but rather that the shaping-which would occur in any region and for any data set-is particularly notable due to the pressures of making maps under military occupation.

One way to see the intricate relationships between landscape and cartographic practices is to focus on the outer border of the West Bank as depicted in figure 1. This border is the subject of an iconic story that illustrates the violence that is often inherent in efforts to remake the ground to meet the map. To those familiar with

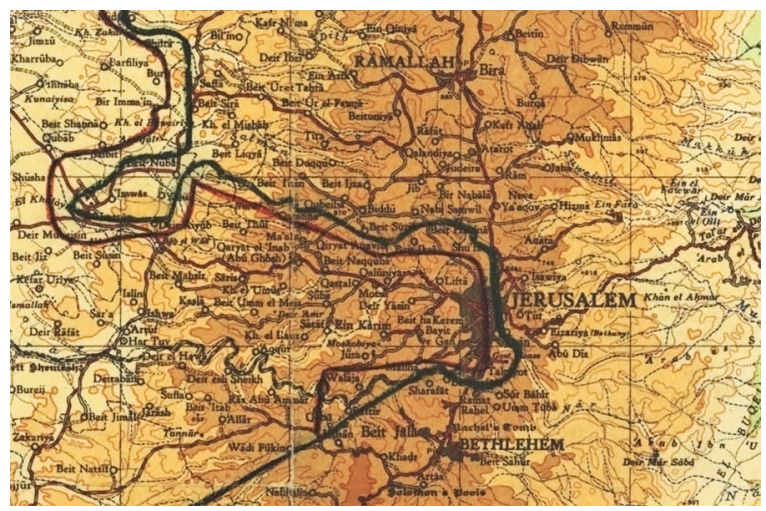

Figure 2 A detail of a British map of Jerusalem with a handdrawn border. This image is taken from the map where the armistice line was first drawn during cease-fire negotiations (SOP 1949). This map is the responsibility of the author. Updated UN maps can be found at www.ochaopt.org (accessed June 29, 2016).

cartography in the region, this border is immediately intelligible as one of several versions of what is sometimes termed the Green Line, the border that some use to denote the outermost boundary of the West Bank. As territories, the West Bank and Gaza Strip were first named and marked off during the armistice agreements after the war that followed the declaration of the state of Israel in 1948. The negotiators physically drew the boundary onto a British colonial map of the region using a thick wax pencil (fig. 2). The line appeared to be sufficient on the large-scale map where it was drawn, but that changed as the boundary began to be imposed on the ground. Demarcating the land required zooming in, so to speak, from a regional scale to a local scale, to pinpoint exactly where the line should be marked out. However, at that finer scale, the line itself became as thick as several buildings. Thus, in the process of enforcing the new border, significant portions of entire neighborhoods were found to lie inside the border line. Such demarcations are evident in figure 2, where the relevant border is the thick black vertical line at right that cuts through Jerusalem (Blake 1995; Brawer 1990; Cameron 2011).

So, after 1948, making the map required reshaping the land, with an associated loss of homes and livelihoods. This reshaping is evident in the attempts just described, which sought to impose the heavily militarized armistice boundaries on the ground. However, these changes were reversed after Israel occupied the West Bank and Gaza Strip in 1967, when the occupying military initiated an active effort to obscure the Green Line both on maps and on the ground (Brawer 1990). Notably, this effort included the process of building Israeli settlements in 
the West Bank, which has evolved over the years into an intricate system of segregation and control over Palestinians. Alterations were made again in 1994, as part of negotiations related to the Oslo accords, which saw the founding of the PA. However, the final boundaries and possible land swaps have yet to be determined, a situation that is complicated by a series of splits and rapprochements between the PA, whose center of influence lies in the West Bank, and Hamas, which has greater control in Gaza.

So efforts to impose a newly created boundary were followed by equally forceful attempts to erase it, but neither was definitive. Partly as a result of these various attempts to create and erase boundaries in the West Bank and Gaza Strip, the late 1990s saw the growth of communities of professional Palestinian cartographers in the region, as one aspect of the broader commitment to sumud. Indeed, after its founding, the PA quickly adopted GIS in part to bring its own maps to the negotiating table and in part to support the development efforts of the newly formed government. Additionally, over the years there have been numerous atlases (e.g., ARIJ 2009; see also Tawil-Souri 2012) produced, as well as ongoing efforts to document the locations of demolished Palestinian villages and erased cultural geography (Abu Sitta 2004, 2007; Davis 2011; Hadawi 1970; Khalidi 1992).

In this context, the continuing lack of a final status agreement over the borders of the West Bank represents yet another challenge to Palestinian stasis in the region. It also increases the labor on the part of the PA when making maps like figure 1 , because there are a host of considerations involved in selecting which border to use and the political message it will send. Possible borders include different versions of the Green Line, as well as the line of the Wall currently being built inside the West Bank, which in many places acts as the effective border. Furthermore, data files for these competing boundaries, and related aerial photographs, are not always easily accessible to Palestinian officials, requiring ongoing negotiation in terms of choosing which border to display, as well as acquiring relevant data files, whether from Israelis or international organizations.

For instance, the boundary in use in the Israeli military might be made at a higher resolution - accounting, for example, for minute shifts in the earth's surface over time or changes in urban areas-than the more symbolic and readily available boundary depicted in figure 1, which is based largely on that first broad boundary as it was drawn onto the British colonial map during the armistice agreements (fig. 2). The increasingly stringent segregation can also prevent PA officials from updating British boundaries themselves using GPS devices, which is considered common practice among professional cartographers. The next two sections investigate the effects of this persistent British influence, combined with 
the restrictions on GPS fieldwork, and demonstrate the effects of landscapes upon the very constitution of scientific knowledge.

\section{Digital Roads through a Demolished Village: The Obduracies of Colonial Maps}

One way to begin to see these effects is to trace the roads that are shown as dark black lines in figure 1. While many borders are intended to encircle geographic areas, by contrast roads cross through them, facilitating transportation across boundaries. Road maps emphasize the empirical, since the intention is to display where one might be able to travel, at least in theory. Yet although the data in figure 1 are relatively detailed, it would be a challenge to use these data to get around the West Bank. To understand why, it is first necessary to explore the enduring stasis of British maps in the region and their ability to remain as prominent material artifacts amid so much destruction.

The British relinquished their League of Nations mandate in Palestine in 1948. In their wake, they left a trove of carefully executed empirical and topographical maps, the result of efforts that stretched back decades (Gavish 2005; Moscrop 2000). The ensuing years would witness wholesale changes in the landscape as Palestinian towns, toponymy, and livelihoods were forcefully erased by the new Israeli state (Abu El-Haj 2003), while many of those with the expertise to keep up Palestinian knowledge forms like cisterns and irrigation works were not allowed to return to their former homes (Benvenisti 2000; SOP 1945: 4). Yet there was a discrepancy in the value attributed to different forms of knowledge on the part of the Israeli officials. For although British rule had been resolutely resisted by the Jewish community and Palestinians alike, the Israeli agents nonetheless actively cataloged and conserved large caches of British colonial maps.

Over time, these acts of conservation became something of a self-fulfilling prophecy. The British maps were preserved because they were believed to be significant, and in subsequent years they would become significant precisely because they had been preserved. Overall, the preservation and circulation of British maps have had a concerted effect on mapmaking in the nascent Palestinian state. The PA drew time and again on British sources not due to some overriding belief in the accuracy of the older maps but rather out of pragmatic necessity. For map data must come from somewhere. It can take years for a professional team to draw the first maps of an unmapped region, a process that might involve tracing hundreds of thousands of lines, not to mention establishing a system of geographic coordinates and conducting extensive surveys in the landscape. Using existing maps 
is generally far more practical and expedient than starting from scratch, but it requires access to those maps. Because they were widely preserved, the British maps were more accessible to the PA than other sources of data, many of which were held back by the Israeli government.

The ultimate impact of the use of British Mandate maps becomes clear through a closer examination of the specific digital methods that were used to transform the maps into digital image files and incorporate them into the computer. PA and related cartographic efforts have had a digital focus since the beginning, and one of the first tasks the cartographers undertook was to scan the British maps. However, scanning was not sufficient to produce digital maps. After scanning, the PA employees needed to digitize the image files in the cartographic sense. To digitize an image, a cartographer uses the mouse to trace over the relevant features of the scanned image, so that the GIS program can record the length, position, and direction of every small curve or area (fig. 3). For example, a cartographer might open an image of a road map and then laboriously mouse over the road lines one by one, drawing on top of the scanned map and thereby incorporating its information into the GIS program. Even for rudimentary maps, digitization is a time-consuming and labor-intensive process. "We started from zero. . . . We had two employees spending eight months working twentyfour hours a day to digitize the contour lines of the British 1936 maps," noted one

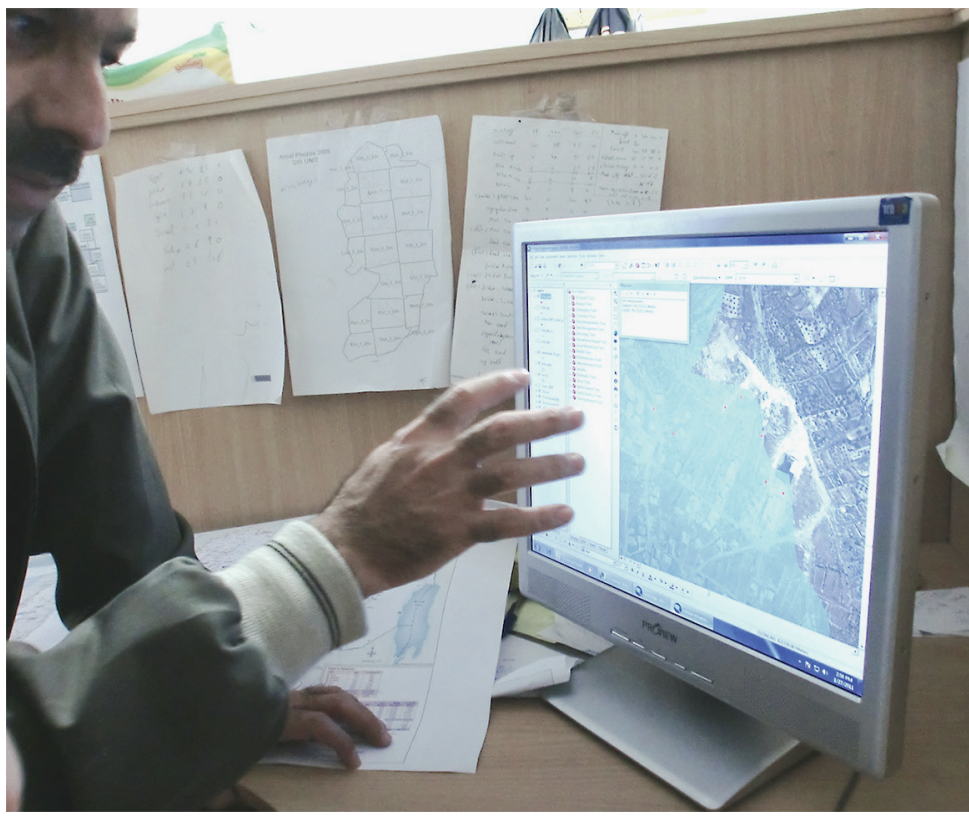

Figure 3 A professional cartographer and GIS analyst explains the process of digitizing an aerial photograph. Photograph by the author former PA cartographer (2011). ${ }^{6}$ Furthermore, this labor would need to be undertaken before even beginning to make a map. Otherwise, one might open a blank map file in the GIS program to find there were no data—no lines, no shades, no features — to add to it.

6. To protect confidentiality, the names of some interviewees have been withheld by mutual agreement. 
So the PA's high-tech mapping industry began with professionally trained cartographers laboriously tracing colonial maps. While it is not unusual for cartographers to draw on existing maps for digitization purposes, the use of British maps was far more extensive than it would otherwise have been, due both to the prevalence of well-preserved British maps and to the mobility restrictions imposed by the Israeli occupation. That contrasts with the development of GIS in Israel in the mid-1980s and early 1990s, when data from existing maps were routinely verified by field surveys using handheld GPS, a privilege afforded to Israeli cartographers even within the Palestinian Territories due to the occupation (Peled 1996: 492). Yet in addition to being time-consuming, digitization also selectively influences the digital files that are produced. For although the user can decide which parts of each map to include and which to omit, it is not possible to digitize layers that are not present on the original map. So the type of map that is used conditions the data that result.

For example, this can be seen in the roads in figures 1 and 5, which, although they draw on data made public as recently as 2008, nonetheless show a marked influence of British colonial maps of the kind that is representative of the PA's early work in the 1990s. The scales and resolution of these roads, and their associated levels of detail, are particularly deserving of further examination. In contrast to the armistice boundary drawn on a paper British map described earlier, whose line grew thick at finer scales, digital maps are intended to allow for numerous scales. The GIS mapmaking program redraws the maps in greater detail as one zooms in, as can be seen on websites like Google Maps and OpenStreetMap. This contrasts with a basic image file, which has one fixed scale and resolution. However, even with GIS, the possibilities are limited because, ultimately, map data have their finest scale built into them. If one zooms in closer than that finest scale, then just as in a basic image, the digital lines quickly start to appear chunky and pixelated.

Like all data, the data in figure 1 have just such a limit. For although the roads appear at first to be quite detailed, just by zooming in, as seen in figure 5 , it becomes clear that fewer than ten roads are depicted even in major cities like Jerusalem and Ramallah. ${ }^{7}$ This limitation is a direct result of the practice of digitizing the British colonial maps (and related sources that also drew on British sources), which were paper maps made at fixed scales. Due to the digitization

7. These are far from the finest-scale data currently available to the PA and Palestinian NGOs. However, they are representative of the major data sets that were in widespread use, even in governance and technical circles, prior to 2005 (see, e.g., MOPIC 1996, 1998). 
process, the PA maps were restricted to the same scales that those paper maps used. Yet through digitization alone, the PA cartographers could not improve on the scale of the British data. They couldn't make more detailed features appear if they weren't there in the original document. Instead, they could simply try to trace the British maps as accurately as possible. And indeed, the road lines in figure 1 replicate with precision the lines for roads in British maps, such as the British map in figure 2. Historically, the British controlled a territory much larger than the PA does. That meant that it would be quite difficult for PA cartographers to make maps at any scale that was finer than the entire West Bank. Strikingly, early PA maps replicated exactly this scale and no finer (MOPIC 1996, 1998). As a result, these initial maps were useful for symbolic political purposes but were less helpful for the crucial needs of daily governance in the nascent state.

\section{Plundered Data and Raided Institutions}

If the roads show the colonial influence within digital technology, then the shaded areas of figures 1 and 5, which indicate urban or built-up zones, reveal the challenges to overcoming that colonial data on the ground. Yet before examining the effects on the depiction of urban areas, it is necessary to describe those challenges further. For if cartographic digitization was the priority before 2005, in the ensuing years cartographers have made a concerted effort to update the British data using GPS and surveying equipment. But that has not been a straightforward process, and the persistence of British maps contrasts sharply with the ongoing and often violent attacks that endanger the stasis of Palestinian institutions and NGOs.

Over the years, the Israeli military has made numerous incursions into Palestinian institutions. Elia Zureik (2001: 212) notes that after the Israeli invasion of Lebanon in 1982, the papers of the Palestine Liberation Organization (PLO) were transported wholesale to Israel. Some of them were later returned, presumably after the Israeli military had made copies. In addition, the Palestine Research Center, affiliated with the PLO, was subject to forced closure in the 1980s. Its records were seized, then returned two years later (Jiryis and Qallab 1985). The raids only intensified during the second intifada. In May 2001, the Israeli military took over the Orient House, which had long served as the de facto PLO headquarters and which, in this capacity, had been producing maps without GIS since the 1980s (Orient House 2005; Tufakji, 2016). The staff claimed that the entire archival collection was impounded, as were dozens of computers (Orient House 2001a, 2001b, 2001c, 2001d, 2001e). The Israeli military soon also began to directly target the $\mathrm{PA}$, its ostensible partner in peace negotiations. 
"What I fear most is the magnitude of the data that were stolen" (Abu-Libdeh 2001d; Claudet 2001). These were the words of Hassan Abu-Libdeh, then the director of the Palestinian Central Bureau of Statistics (PCBS), on December 5, 2001. Less than three months after $9 / 11$ and less than two months before the Taba Summit, which had the aim of establishing a final status agreement between Israel and the PA, the Israeli military forcefully raided the PCBS, which conducts the PA's population census, and detained those present in the building. The apparent goal of the raid was to gather the data on Palestinians that the PA had been collecting in its governance efforts. Speaking to the press, Abu-Libdeh (2001a, 2001b, 2001c; Claudet 2001) worried specifically about data-namely, that Israel would continue raiding offices to gain access to the PA's geographic and population data and, at the same time, destroying its means of storing and using the data. By preventing the PA from fulfilling its mandate, the raid could thus be seen as an attempt to disrupt the stasis of the PA not only during the raid itself but also in the future. ${ }^{8}$

In this context, PA cartographers routinely mentioned fears that their amassing of data might be in vain (former Orient House cartographer 2010; former PA cartographer 2011). The ongoing raids also played into the refashioned landscapes of NGOs and PA offices described above, to the extent that the relocation of Palestinian organizations accelerated their move to the West Bank side of the Wall and influenced their ability to collect data about the Jerusalem side. Given that each move required a tremendous effort and outlay of funds, organizations thus have been made mobile in ways that have come to diminish their institutional stasis. In addition, the forms of stasis and mobility, of both cartographers and their institutions, have combined to restrict the overall extent of their data. Yet especially since 2005, this has not been absolute. The scope and geography of those restrictions are themselves quite varied, and I delve further into their specific effects below.

\section{Staying Put, on the Road in Palestine}

The PA's partial sovereignty in the West Bank shapes the extent of the urban areas in figures 1 and 5, including their scope and boundaries. One way to see this influence is to focus on the background space of the images, the areas of negative space that are left blank. Indeed, the reasons why they are shown without features can have everything to do with regimes of mobility and stasis in the region.

8. Abu-Libdeh has since been brought up on corruption charges - charges, however, that appear to be unrelated to his time as the director of the PCBS and which he claims are politically motivated (Ha'aretz 2011). 
Although the urban areas in figures 1 and 5 have been updated from the original British data, the very seamlessness of the images belies the complexity of that updating process. It is therefore worth exploring it in greater detail. To do so, it helps to turn to figure 4, which illustrates the limited sovereignty granted to the Palestinians under the Oslo accords and successive agreements. Figure 4 depicts Israeli-controlled areas in dark gray, including both natural reserves and the region known as Area $\mathrm{C}$, which is under full Israeli sovereignty. Together, they contain the majority of the West Bank, surrounding the multiplicitous smaller Areas A and B. Areas A and $\mathrm{B}$ are combined in lighter gray, and, respectively, they fall under full and partial Palestinian control. Since Areas A and B are islands of limited sovereignty, nearly every Palestinian person traveling within the West Bank must, at some point, go through Israeli-controlled Area C and therefore risk being subject to checkpoints, searches, and detention. This restricted mobility in turn shapes how data can be collected in the field.

As noted earlier, cartographic field surveys are the most common way to update British map data. Such surveys involve using tools like handheld or tripod-mounted GPS units-extended versions of the mapping applications available

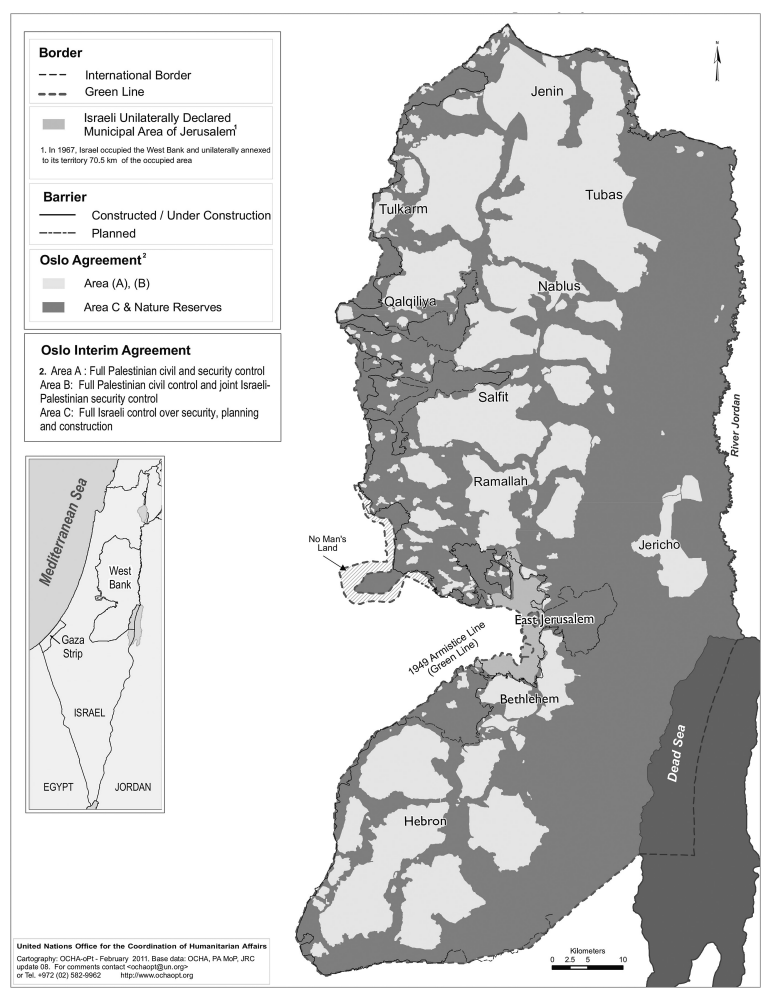

Figure 4 A map of the West Bank that indicates Areas A and B, which are under full or partial Palestinian control, combined in light gray. Area $C$ and Israeli natural reserves, the majority of the West Bank, are combined in dark gray. This map is excerpted from UNOCHA-OPT 2011. This map is the responsibility of the author. Updated UN maps can be found at www.ochaopt.org (accessed June 29, 2016). on many mobile phones - to record precise locations for the sometimes hundreds or thousands of buildings, roads, crops, and other features in a single town or district. Mobility is central to surveying, and it is one obvious factor that affects the PA's ability to collect data. However, the cartographers I spoke with repeatedly mentioned that, in many cases, the challenge is not simply accessing different areas. At one time or another, it is possible to reach many parts of the West Bank, with the obvious exception of the settlements and closed military zones (PA transport cartographer 2011; PA transport engineer 2011; Ingham 2013). However, they face tremendous difficulties in the field when attempting to stay in one place for 
an extended period of time without the intervention of settlers or the military. It takes time to observe and record data, and surveys require numerous technicians, sometimes with heavy equipment. So in order to survey an area per standard practice, cartographers not only have to travel there, but they also need to remain. Thus stasis is just as crucial to surveying as mobility is.

The complex quilt of Areas A, B, and C (fig. 4) also present particular challenges to attempts to achieve reliable stasis. Particularly in Areas B and C, where the Israeli military has partial or full control, cartographers spoke of the lengths they went to, to avoid drawing attention to themselves - and of the Israeli military soldiers who nevertheless inevitably appeared if they stayed in some locations for more than a brief moment. In such contexts, the cartographers' visible possession of expensive-looking instruments in itself often aroused suspicion. As one pointed out: "We can move in Area $\mathrm{C}$, but if we have equipment, it is very dangerous for us. If we have cameras or GPS, and if the soldiers stop us, they can arrest us. Two years ago, they arrested me and [my colleague] because they caught us in Area C ... [taking] photos of demolished houses and [recording] GPS points" (Palestinian NGO cartographer 2011).

Many of those I worked with had been arrested at one time or another simply for carrying out their professional duties, which were officially legal and scientific. Given that Areas A and B are surrounded by Area C, another pair of cartographers mentioned that, although their survey was restricted to Areas A and B, while traveling they often had to pass through Israeli checkpoints in Area C. They then would need to hide their GPS units and cameras to avoid confiscation and summary arrest. The advent of small, pocket-size GPS units made their jobs easier, one engineer noted, because they "look like mobile phones," although sometimes phones were also confiscated (PA transport cartographer 2011; PA transport engineer 2011).

For these reasons, to update their maps (e.g., fig. 5) in recent years PA and NGO cartographers have begun to develop the technique of mobile surveying, using handheld GPS units and conducting their work fully within a vehicle. One mentioned that although his groups work in Area C, "We are very careful. Like when we use GPS, we [take it] in the car and drive the car without anyone seeing anything" (Palestinian NGO cartographer 2011; PA civil engineer 2011). Rather than visiting a single location one time to take a detailed reading, they used cars to visit several times, for short periods, to take quick readings of different aspects of the landscape that could then be combined. So, while their computer labs were gutted from within by the Israeli military during raids, PA cartographers in the field were confined to their cars, which became circulating cartographic laborato- 


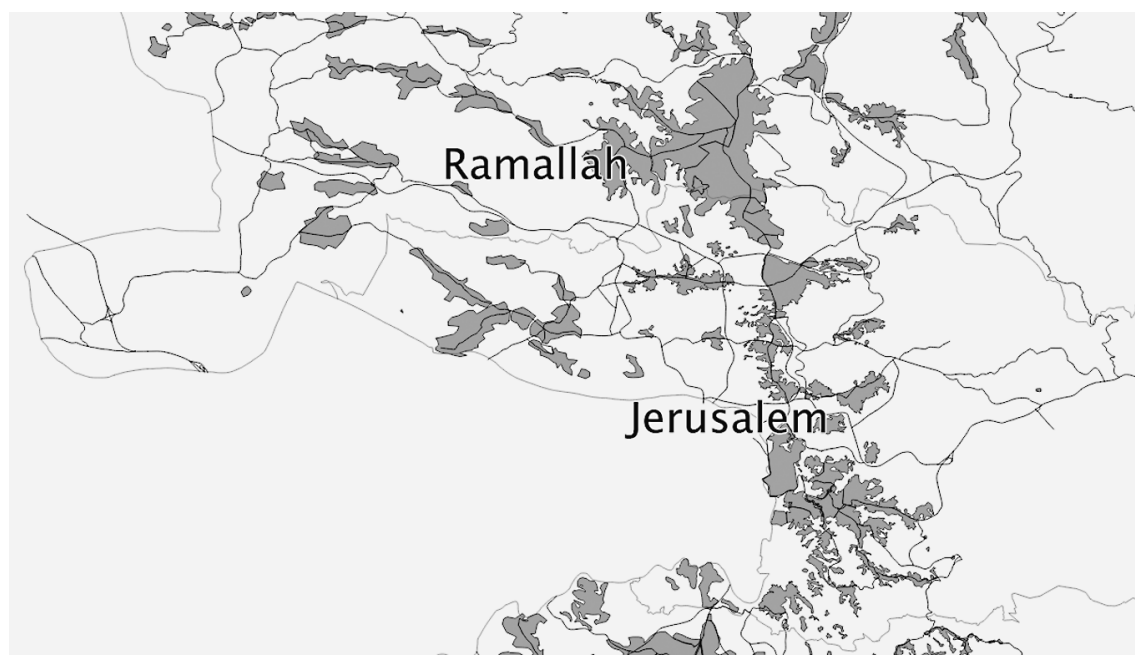

Figure 5 A screenshot of detail from figure 1, centered on Jerusalem. Label placement is approximate. It demonstrates how aspects of the display can be determined by the program, although there are also options for customization. Map by the author. Data appear courtesy of Global Map of Palestine @ ISCGM / Palestinian National Authority, Ministry of Planning, Geographic Center and Technical Support, www.mopad.pna.ps/en/ (accessed March 2, 2016).

ries (Lee and LiPuma 2002). Their stasis and their mobility thus were intertwined, and they strengthened Palestinian stasis not by rendering themselves immobile but by being constantly on the move, embracing the car as a technological space in its own right, a way of being static-in-motion. ${ }^{9}$

However, there is a complicated relationship between the extent of the area where data could be collected for technical reasons and the extent where cartographers were able to move and remain. Even in a car, PA cartographers cannot conduct surveys throughout Area $\mathrm{C}$ - even if, as noted, occasionally they do enter it. Indeed, sometimes they enter Area $\mathrm{C}$ without even realizing it. For although settlements and settler roads are well marked with signs, and blocked by checkpoints, the boundaries between Areas A, B, and C are often not visible at ground level. The Israeli authorities generally provide such boundary information only for relatively large-scale maps of the West Bank, so the internal boundaries can be difficult for even cartographic agencies to determine at finer scales (geography professor 2011; Palestinian NGO cartographer 2011). During my fieldwork, at least one call per day would come in from landowners who wished to know whether

9. My thanks go to an anonymous reviewer for this suggestion, including the phrasing. 
their homes fell within Area A, B, or C or some combination of the three. Even a home that was on the border, with only one backyard or room in an Israelicontrolled district, was considered grounds for demolition by the Israeli authorities (ARIJ 2006). Thus the inability to update data for Area $C$ in particular stems from cartographers' inability to obtain reliable stasis there due to the occupation (former PA cartographer 2011). Under such ambiguous circumstances, those I spoke with generally limit the extent of their data collection to Areas A and B alone, as much as it can be determined.

These circumscribed forms of stasis and mobility combine to influence the background spaces of PA maps. For example, by comparing figure 4 with figures 1 and 5, it is possible to see that the updated, shaded urban areas in figure 1 often correspond exactly to Areas A and B as they are depicted in figure 4. The map in figure 1 includes detailed updates in major cities in Area A and to a lesser extent in Area B. However, much of Area $\mathrm{C}$ relies heavily on the digitized versions of decades-old British maps. As a result, Area $\mathrm{C}$ is depicted as being mostly blank, even where it is heavily populated. Of course, the PA has attained sovereignty in Areas A and B precisely because those areas are considered to be Palestinian population centers, so it is not entirely surprising that the built-up areas in figure 1 would generally overlap with the lighter shaded islands in figure 4 . But what is remarkable is how precisely they correspond and that there are almost no updates for the towns and villages in Area C.

At an international level, Palestinian cartographers are expected to map every area of the West Bank at an equal level of detail, yet they are not granted consistent mobility or stasis in that same region. The results of these restrictions even appear to efface themselves, for the updates in the urban areas mesh seamlessly with the blank negative space in the more rural Area C. So, blank areas are likely to be seen not as the result of an absence of data but instead as reflecting empty space on the ground. This has crucial implications for policy and political negotiations. For under these conditions, the blank areas on maps can become self-perpetuating. Palestinian populations are first pushed onto blank areas, then prevented from mapping the "blankest" portions of those areas, and then told that the unmapped areas can be seized precisely because they are blank. The obduracy of these erasures, which repeat across maps and data sets, is thereby also a type of anticipation, a forceful backgrounding of particular people and landscapes. It can have dire consequences because it helps to ensure that those communities will go unmapped today and, in the current geopolitical climate, possibly be demolished in the near future. 
Despite the vast differences between the British and Israeli colonial regimes, they combine to circumscribe the possibilities for the scale and extent of PA maps. As a result, particularly in the early days of the PA, its maps were almost exclusively broader scale and largely symbolic. That was partly due to the fact that Palestinian cartography was formed in segregated landscapes that had exclusionary passages - stable but "never fixed" pathways of least resistance (Peters, Kloppenburg, and Wyatt 2010: 354-55) — for both the stasis and mobility of data. British maps were preserved, and therefore digitizing them became the easiest or most obvious passage for the cartographers to follow. To build a cartographic data infrastructure, both through digitization and GPS surveys, the cartographers also had to reshape existing passages, for example, by conducting GPS surveys on the road, to refashion their own mobility and stasis.

The PA's ability to produce reliable maps despite the myriad uncertainties analyzed here is in part a testament to the extent to which Palestinian cartographers have been able to collect and piece together British data at all, finding ways to preserve their collections despite repeated raids. As such, it demonstrates the theoretical and practical innovations, with respect to passages of mobility and stasis, that are involved in the material reconfigurations that are necessary to make their maps. Forms of material innovation, such as the mobile surveys, risk remaining unacknowledged in reports and oversight methods that sometimes focus on results, like paper maps, instead of the often hidden work of infrastructure building and passage reshaping. It is a kind of innovation that asks for us to take stasis more seriously. For as with so many forms of digital media and knowledge, the apparent seamlessness of PA maps belies both the stark injustices and the nuanced complexity of the landscapes where they were produced.

\section{References}

Abourahme, Nasser, and Laura Ribeiro. 2010. "Re-weaving Fragmented SpaceTime: Notes from a Mapping Project in Palestine.” Lo Squaderno, no. 15: 37-43.

Abu El-Haj, Nadia. 2003. "Reflections on Archaeology and Israeli SettlerNationhood." Radical History Review, no. 86: 149-63.

Abu-Libdeh, Hassan. 2001a. "An Urgent Appeal: The Israeli Military Forces

Take Over PCBS.” Press release, December 5. Ramallah: Palestine Central Bureau of Statistics. 

2001b. "Update No. 2: The Israeli Military Forces Withdraw from the PCBS Premises, Leaving behind Ruins, Stolen Property, Missing Files, Missing Computers, and Missing Datasets." Press release, December 6. Ramallah: Palestine Central Bureau of Statistics.

_ 2001c. "Update No. 3: The Day After; PCBS Inspects Its Hardware for Harmful Devices.” Press release, December 7. Ramallah: Palestine Central Bureau of Statistics.

- 2001d. "Update No. 4: War against the PCBS; the Days after, PCBS Response to IDF Claims." Press release, December 8. Ramallah: Palestine Central Bureau of Statistics.

Abu Sitta, Salman. 2004. The Atlas of Palestine, 1948. London: Palestine Land Society.

- 2007. The Return Journey: A Guide to the Ethnically Cleansed and Present Palestinians Towns, Villages, and Holy Sites in English, Arabic, and Hebrew. London: Palestine Land Society. www.palestineremembered.com/Acre/Maps /Story2319.html.

Allen, Lori. 2008. "Getting by the Occupation: How Violence Became Normal during the Second Palestinian Intifada." Cultural Anthropology 23, no. 3: 453-87.

- 2013. The Rise and Fall of Human Rights: Cynicism and Politics in Occupied Palestine. Stanford Studies in Human Rights. Stanford, CA: Stanford University Press.

Amnesty International. 2003. "Israel and the Occupied Territories: Surviving under Siege; The Impact of Movement Restrictions on the Right to Work." MDE 15/001/2003. London: Amnesty International.

Aouragh, Miriyam. 2011a. "Confined Offline, Traversing Online Palestinian Mobility through the Prism of the Internet." Mobilities 6, no. 3: 375-97.

- 2011b. Palestine Online: Transnationalism, Communications, and the Reinvention of Identity. London: I. B. Tauris.

—. 2015a. "Revolutionary Manoeuvrings: Palestinian Activism between Cybercide, and Cyber Intifada." In Media and Political Contestation in the Contemporary Arab World: A Decade of Change, edited by Lena Jayyushi and Anne Sofie Roald, 129-60. Basingstoke: Palgrave Macmillan.

- 2015b. "Revolutions, the Internet, and Orientalist Reminiscence." In Revolutionary Egypt: Connecting Domestic and International Struggles, edited by Reem Abou-El-Fadl, 257-78. London: Routledge.

Aouragh, Miriyam, and Paula Chakravartty. 2016. "Infrastructures of Empire: 
Towards a Critical Geopolitics of Media and Information Studies.” Media, Culture and Society 38, no. 4: 559-75.

ARIJ (Applied Research Institute Jerusalem). 2009. A Geopolitical Atlas of the Occupied Palestinian Territory. Bethlehem: ARIJ.

- 2016. Israeli Military Orders Database. orders.arij.org/ (accessed June 29, 2016).

Balibar, Étienne. 1990. “The Nation Form: History and Ideology.” Review 13, no. 3: 329-61.

Benvenisti, Meron. 2000. Sacred Landscape: The Buried History of the Holy Land since 1948. Berkeley: University of California Press.

Bier, Jess. In press. Mapping Israel, Mapping Palestine: Occupied Landscapes of International Technoscience. Cambridge, MA: MIT Press.

Bijker, Wiebe E. 1995. Of Bicycles, Bakelites, and Bulbs: Toward a Theory of Sociotechnical Change. Cambridge, MA: MIT Press.

Bijker, Wiebe E., Thomas P. Hughes, and Trevor Pinch, eds. 2012. The Social Construction of Technological Systems: New Directions in the Sociology and History of Technology. Cambridge, MA: MIT Press.

Blake, Gerald. 1995. "The Depiction of International Boundaries on Topographic Maps." Boundary and Security Bulletin 3, no. 1: 44-50.

Brawer, Moshe. 1990. “The 'Green Line': Functions and Impacts of an IsraeliArab Superimposed Boundary." In International Boundaries and Boundary Conflict Resolution, edited by Carl Grundy-Warr, 63-74. Durham, UK: Boundaries Research Press.

B'Tselem. 2004. “Forbidden Roads: Israel's Discriminatory Road Regime in the West Bank.” Jerusalem: B'Tselem.

Cameron, Angus. 2011. "Ground Zero: The Semiotics of the Boundary Line." Social Semiotics 21, no. 3: 417-34.

Claudet, Sophie. 2001. "Israeli Army Raid Sets Dangerous New Precedent." Daily Star, December 10.

Cosgrove, Denis. 2008. Geography and Vision: Seeing, Imagining, and Representing the World. International Library of Human Geography 12. London: I. B. Tauris.

Crampton, Jeremy W. 2001. "Maps as Social Constructions: Power, Communication, and Visualization." Progress in Human Geography 25, no. 2: 235-52.

- 2010. Mapping: A Critical Introduction to Cartography and GIS. Malden, MA: Wiley-Blackwell.

Crampton, Jeremy W., and John Krygier. 2006. "An Introduction to Critical Car- 
tography." Acme: An International E-Journal for Critical Geographies 4, no. 1: $11-33$.

Cresswell, Tim. 1999. "Embodiment, Power, and the Politics of Mobility: The Case of Female Tramps and Hobos." Transactions of the Institute of British Geographers 24, no. 2: 175-92.

- 2011. "Mobilities I: Catching Up." Progress in Human Geography 35, no. 4: 550-58.

Davis, Rochelle. 2011. Palestinian Village Histories: Geographies of the Displaced. Stanford Studies in Middle Eastern and Islamic Societies and Cultures. Stanford, CA: Stanford University Press.

Dodge, Martin, Rob Kitchin, and Chris Perkins, eds. 2009. Rethinking Maps: New Frontiers in Cartographic Theory. Routledge Studies in Human Geography. New York: Routledge.

- 2011. The Map Reader: Theories of Mapping Practice and Cartographic Representation. Chichester, UK: Wiley-Blackwell.

Edney, Matthew H. 1997. Mapping an Empire: The Geographical Construction of British India, 1765-1843. Chicago: University of Chicago Press.

Former Orient House cartographer. 2010. Author interview, Jerusalem, July 2.

Former PA cartographer. 2011a. Author interview, Ramallah, January 18.

Gavish, Dov. 2005. A Survey of Palestine under the British Mandate, 1920-1948. New York: Routledge.

Geography professor. 2011b. Author interview, Birzeit, January 18.

Ha'aretz. 2011. "Palestinian Economy Minister Charged with Embezzlement, Insider Trading." November 29.

Hadawi, Sami. 1970. "Village Statistics, 1945: A Classification of Land and Area Ownership in Palestine.” Beirut: Palestine Liberation Organization Research Center.

Haraway, Donna. 1988. "Situated Knowledges: The Science Question in Feminism and the Privilege of Partial Perspective." Feminist Studies 14, no. 3: 575-99.

Harker, Christopher. 2009. "Student Im/mobility in Birzeit, Palestine.” Mobilities 4, no. 1: 11-35.

Ingham, Richard. 2013. "Cheers for Palestinian Film of Love and Betrayal." Daily Star, May 20.

Jiryis, Sabri, and Salah Qallab. 1985. "The Palestine Research Center.” Journal of Palestine Studies 14, no. 4: 185-87.

Khalidi, Walid. 1992. All That Remains: The Palestinian Villages Occupied 
and Depopulated by Israel in 1948. Washington, DC: Institute for Palestine Studies.

Kwan, Mei-Po. 2002. "Feminist Visualization: Re-envisioning GIS as a Method in Feminist Geographic Research.” Annals of the Association of American Geographers 92, no. 4: 645-61.

Latour, Bruno. 1993. We Have Never Been Modern. Translated by Catherine Porter. Cambridge, MA: Harvard University Press.

Latour, Bruno, and Steve Woolgar. 1986. Laboratory Life: The Construction of Scientific Facts. Princeton, NJ: Princeton University Press.

Lee, Benjamin, and Edward LiPuma. 2002. "Cultures of Circulation: The Imaginations of Modernity." Public Culture 14, no. 1: 191-213.

Leuenberger, Christine. 2012. "Map-Making for Palestinian State-Making.” Arab World Geographer 16, no. 1: 54-74.

Leuenberger, Christine, and Ahmad El-Atrash. 2014. "Mosquitoes Don't Carry Visas: Walls, Environments, and the Hope for Cooperation in Palestine/Israel." Palestine-Israel Journal of Politics, Economics and Culture 19, no. 4, and 20, no. 1: 68-78.

Leuenberger, Christine, and Izhak Schnell. 2010. "The Politics of Maps: Constructing National Territories in Israel.” Social Studies of Science 40, no. 6: 803-42.

MacKenzie, Donald A. 2006. An Engine, Not a Camera: How Financial Models Shape Markets. Inside Technology. Cambridge, MA: MIT Press.

Mitchell, Timothy. 2002. Rule of Experts: Egypt, Techno-Politics, Modernity. Berkeley: University of California Press.

MOPIC (Ministry of Planning and International Cooperation). 1996. "Landscape Assessment of the West Bank Governorates: Emergency Natural Resources Protection Plan.” Ramallah: Palestinian National Authority, MOPIC, Directorate for Urban and Rural Planning.

_. 1998. "The Regional Plan for the West Bank Governorates.” Ramallah: Palestinian National Authority, MOPIC.

Moscrop, John James. 2000. Measuring Jerusalem: The Palestine Exploration Fund and British Interests in the Holy Land. London: Leicester University Press.

Orient House. 2001a. "The Looted Archives of the Orient House." Editorial. Jerusalem Quarterly, no. 13: 3-5.

. 2001b. "Israel Continues Its Efforts to Strangle the Orient House." Press release, July 20. 
— 2001c. "Orient House Begins Its Commemoration Ceremony despite Israeli Obstacles.” Press release, July 17.

—. 2001d. "Press Release from the Orient House." August 30.

—. 2001e. "Urgent Appeal from the Orient House." Press release, August 14.

- 2005. "Statement from the Orient House to the International Community." Press release, July 19.

PA civil engineer. 2011. Author interview, Bethlehem, March 3.

PA transport cartographer. 2011. Author interview, Bethlehem, January 27.

PA transport engineer. 2011. Author interview, Bethlehem, January 27.

Palestinian NGO cartographer. 2011. Author interview, Bethlehem, January 27.

Pavlovskaya, Marianna E. 2002. "Mapping Urban Change and Changing GIS: Other Views of Economic Restructuring." Gender, Place and Culture 9, no. 3: 281-89.

Peled, Ammatzia. 1996. "Generating the Israel National GIS.” In The Mosaic of Israeli Geography, edited by Yehuda Gradus and Gabriel Lipshitz, 485-96. Beersheba: Negev Center for Regional Development and Ben-Gurion University of the Negev Press.

Peters, Peter, Sanneke Kloppenburg, and Sally Wyatt. 2010. "Co-ordinating Passages: Understanding the Resources Needed for Everyday Mobility." Mobilities 5, no. 3: 349-68.

Pickles, John, ed. 1995. Ground Truth: The Social Implications of Geographic Information Systems. Mappings: Society/Theory/Space. New York: Guilford.

PLO and State of Israel. 1995. Annex I: Protocol concerning Redeployment and Security Arrangements [Oslo II Agreement]. United Nations Peacemaker, September 28, 1995. Peacemaker.un.org/israelopt-oslo1195 (accessed June 29, 2016).

Quiquivix, Linda. 2013. "When the Carob Tree Was the Border: On Autonomy and Palestinian Practices of Figuring It Out." Capitalism, Nature, Socialism 24, no. 3: 170-89.

- 2014. "Art of War, Art of Resistance: Palestinian Counter-Cartography on Google Earth." Annals of the Association of American Geographers 104, no. 3: 444-59. doi:10.1080/00045608.2014.892328.

Rose, Gillian. 1997. "Situating Knowledges: Positionality, Reflexivities, and Other Tactics." Progress in Human Geography 21, no. 3: 305-20.

Smith, Neil. 1992. "Geography, Difference, and the Politics of Scale." In Postmodernism and the Social Sciences, edited by Joe Doherty, Elspeth Graham, and Mo Malek, 57-79. London: Macmillan. 
Söderström, Ola, et al., eds. 2013. Critical Mobilities. Lausanne: EPFL Press. SOP (Survey of Palestine). 1945. "Maps and Publications.” Jaffa: British Mandate, SOP. Uncataloged. Tel Aviv University Map Library. . 1949. "Palestine: North Sheet [Annotated with 1949 Armistice Lines]."

British Mandate Base Survey Drawing and Photo Process Office. Produced April 1946 from January 1946 SOP original. unispal.un.org/DPA/DPR/unispal .nsf/9a798adbf322aff38525617b006d88d7/f03d55e48f77ab698525643b00608d 34/\$FILE/Arm_1949.jpg.

St. Martin, Kevin, and John Wing. 2007. "The Discourse and Discipline of GIS." Cartographica 42, no. 3: 235-48.

Tawil-Souri, Helga. 2012. "Mapping Israel-Palestine.” Political Geography 31, no. 1: $57-60$.

Tawil-Souri, Helga, and Miriyam Aouragh. 2014. "Intifada 3.0? Cyber Colonialism and Palestinian Resistance." Arab Studies Journal 22, no. 1: 102-33.

Tesli, Arne. 2008. "Physical Planning and Institution Building (PPIB): Lessons Learned and Documentation of the PPIB Project in Palestine.” NIBR Report 2008:26. Oslo: Norwegian Institute for Urban and Regional Research. Physical Planning Box 1, Applied Research Institute Jerusalem (ARIJ).

Tufakji, Khalil. 2016 “Maps and Survey Department.” Orient House. www.orient house.org/dept/maps_dept.html (accessed June 29, 2016).

UNOCHA-OPT (United Nations Office for the Coordination of Humanitarian Affairs, Occupied Palestinian Territory). 2009. "Shrinking Space: Urban Contraction and Rural Fragmentation in the Bethlehem Governorate." Jerusalem: UNOCHA-OPT.

—. 2011. "West Bank: Area C Map.” Jerusalem: UNOCHA-OPT.

—. 2012. "West Bank Movement and Access Update." Jerusalem: UNOCHAOPT.

Van Teeffelen, Toine, and Fuad Giacaman. 2008. "Sumud: Resistance in Daily Life." In Challenging the Wall: Toward a Pedagogy of Hope, edited by Toine van Teeffelen, 20-30. Bethlehem: Arab Educational Institute.

Wallach, Yair. 2011. "Trapped in Mirror-Images: The Rhetoric of Maps in Israel/ Palestine." Political Geography 30, no. 7: 358-69.

Winichakul, Thongchai. 1994. Siam Mapped: A History of the Geo-Body of a Nation. Honolulu: University of Hawaii Press.

Wood, Denis. 2010. Rethinking the Power of Maps. New York: Guilford.

Wyatt, Sally. 2003. "Non-users Also Matter: The Construction of Users and Nonusers of the Internet." In How Users Matter: The Co-construction of Users and 
Technology, edited by Nelly Oudshoorn and Trevor Pinch, 67-79. Cambridge, MA: MIT Press.

Yiftachel, Oren. 2009. "Critical Theory and 'Gray Space': Mobilization of the Colonized." City 13, nos. 2-3: 246-63.

Zureik, Elia. 2001. "Constructing Palestine through Surveillance Practices.” British Journal of Middle Eastern Studies 28, no. 2: 205-27.

Jess Bier is an assistant professor at Erasmus University Rotterdam. Previously she was a postdoctoral researcher in the Monitoring Modernity group with Willem Schinkel at the same university. Her first book, Mapping Israel, Mapping Palestine: How Occupied Landscapes Shape Scientific Knowledge, is forthcoming in 2017, and her website is jessbier .org. In her work overall, she analyzes geographies of scientific and technical knowledge. 